\title{
A Study on Phytochemical Analysis and Toxicity Effect of Thevetia peruviana (pers) Merr, against the Filarial Vector, Culex quinquefasiatus Say
}

\author{
S. Uthirasamy*, T. Chitra and G. Manjula \\ Department of Zoology, Erode Arts and Science College, Rangampalayam, \\ Erode (Dt)-638 009, India \\ *Corresponding author
}

\section{A B S T R A C T}

\begin{tabular}{|c|}
\hline Keywords \\
\hline $\begin{array}{l}\text { Culex } \\
\text { quinquefasciatus, } \\
\text { Thevetia peruviana, } \\
\text { Mortality, } \\
\text { Fecundity, } \\
\text { Longevity }\end{array}$ \\
\hline Article Info \\
\hline $\begin{array}{l}\text { Accepted: } \\
15 \text { September } 2019 \\
\text { Available Online: } \\
10 \text { October } 2019\end{array}$ \\
\hline
\end{tabular}

\section{Introduction}

Vector borne diseases, such as insecttransmitted disease remains a major source of illness and death worldwide. Mosquitoes are both aggravating pests and disease-carrying insects that surround us for blood feeding.
Mosquitoes alone transmit disease to more than 700 million people annually. Malaria is a major global health problem. Malaria alone kills 3 million each year, including 1 child every 30 seconds (Shell, 1997). Although mosquito-borne diseases currently represent a greater health problem in tropical and 
subtropical climates, no part of the world is immune to this risk. Control of such diseases is becoming increasingly difficult because of increasing resistance of mosquitoes to pesticides (Ranson et al., 2001). They are about 90 genera and 2500 species of mosquitoes all over the world. Mosquitoes are transmitters of diseases like malaria; filariasis, dengue fever, chikkunguniya and Japanese encephalitis are among the most serious vector borne diseases contribute significantly to poverty and social debility in tropical countries. One of the methods to control these diseases is to control the vectors for the interruption of disease transmission. In the past, synthetic organic chemical insecticides based intervention measures for the control of insect pests and disease vectors have resulted in development of insecticide resistance in some medically important vectors of malaria, filariasis and dengue fever. During the last decade, various studies on natural plant products against mosquito vectors indicate them as possible alternatives to synthetic chemical insecticides (Davidson, 1972).

There has been a large increase in the insecticide resistance of these vectors and it has become a global problem. Insecticide residues in the environment, as a result of using chemical insecticides, have turned the scientist's attention to the use of natural products. During recent decades the use of natural products in the control of mosquitoes has gained high priority (Murty and Jamil, 1987). Mosquito control manages the population of mosquitoes to reduce their damage to human health, economies, and enjoyment. Mosquito control is a vital publichealth practice throughout the world and especially in the tropics because a mosquito spreads many diseases.

Since ancient times, plant products were used in various aspects. However, their use against pests decreased when chemical products became developed. Recently, concerns increased with respect to public health and environmental security requiring detection of natural products that may be used against insect pests. An alternative approach for mosquito control is the use of natural products of plant origin. The botanical insecticides are generally pest specific, readily biodegradable and usually lack toxicity to higher animals (Bowers, 1992). The plant materials are nontoxic to non-target animals, have no phytotoxic properties and leave no residue in the environment. Scientists therefore have embarked on a mission to survey the flora extensively to discover more and more potential plants have insecticidal properties Plant products have been used by traditionally human communities in many parts of the world against the vectors and species of insects. The phytochemicals derived from plant sources can act as larvicides, insect growth regulators, repellents, ovipositional attractants and have deterrent activities. Plantderived materials are usually safer and more ecologically acceptable. They must be tested, however, to judge their efficacy against the target hosts.

Phytochemicals obtained from plants with proven mosquito control potential can be used as an alternative to synthetic insecticides or along with other insecticides under the integrated vector control. Plant products can be used, either as insecticides for killing larvae or adult mosquitoes or as repellents for protection against mosquito bites, depending on the type of activity they possess.

A large number of plant extracts have been reported to have mosquitocidal or repellent activity against mosquito vectors (Sukumar et al., 1991), but very few plant products have shown practical utility for mosquito control. It has been proved that larvicidal measures sustain mosquito population for a short period and require repeated applications of chemicals 
and eventually develop resistance against that chemical.

Plants are rich source of bioactive organic chemicals and synthesize a number of secondary metabolites to serve as defence chemicals against attack. Numerous plant products have been reported either as insecticides for killing larvae or adult mosquitoes or as repellents for mosquito biting and are one of the best alternatives for mosquito control. These chemicals may serve as insecticides, antifeedants, oviposition deterrents, repellents, growth inhibitors, juvenile hormone mimics, moulting hormones, as well as attractants. The botanicals offer an advantage over synthetic pesticides

The plant extracts are easy to prepare, inexpensive and safe for mosquito control which might be used directly as larvicidal and mosquitocidal agents in small volume aquatic habitats or breeding sites of around human dwellings. Botanical pesticides are preferred in comparison to synthetic pesticides, as they are ecofriendly and biodragable (Prakash and Rao, 1977).

Plants are rich source of bioactive organic chemicals and synthesize a number of secondary metabolites to serve as defence chemicals against attack. Numerous plant products have been reported either as insecticides for killing larvae or adult mosquitoes or as repellents for mosquito biting and are one of the best alternatives for mosquito control.

These chemicals may serve as insecticides, antifeedants, oviposition deterrents, repellents, growth inhibitors, juvenile hormone mimics, moulting hormones, as well as attractants. The botanicals offer an advantage over synthetic pesticides as they are less toxic, less prone to be development of resistance and easily biodegradable. plant extracts and 11 oil mixtures were evaluated against the yellow fever mosquito, Aedes aegypti (Linnaeus), the malaria vector, Anopheles stephensi (Liston), and the filariasis and encephalitis vector, Culex quinquefasciatus (Say) (Diptera: Culicidae) using the skin of human volunteers to find out the protection time and repellency (Amer and Mehlhorn, 2006).

Extracts or essential oils from plants may be alternative sources of mosquito larval control agents, as they constitute a rich source of bioactive compounds that are biodegradable into nontoxic products and potentially suitable for use in control of mosquito larvae. In fact, many researchers have reported on the effectiveness of plant extracts or essential oils against mosquito larvae.

The larvicidal activity and repellency of 5 plant essential oils--thyme oil, catnip oil, amyris oil, eucalyptus oil, and cinnamon oil-were tested against 3 mosquito species: Aedes albopictus, Ae. aegypti, and Culex pipiens pallens. Larvicidal activity of these essentials oils was evaluated in the laboratory against 4th instars of each of the 3 mosquito specie.

Anees (2008) studied on the acetone, chloroform, ethyl acetate, hexane, and methanol leaf and flower extracts of Ocimum sanctum against fourth instar larvae of Culex quinquefasciatus. The biological activity of the plant extract might be due to variety of compounds in the plant including phenolics, terpenoids and alkaloids (Rajkumar and Jebanesan, 2005).

The plant extracts are easy to prepare, inexpensive and safe for mosquito control which might be used directly as larvicidal and mosquitocidal agents in small volume aquatic habitats or breeding sites of around human dwellings. Botanical pesticides are preferred in comparison to synthetic pesticides, as they are eco-friendly and biodegradable (Prakash and Rao, 1977). Thevetia peruviana an evergreen shrub, belonging to Apocynanceae 
family, is a very poisonous shrub in nature and the kernels being the most toxic.

This plant is native of central and South America, but now frequently grown throughout the tropical. The shrub or small tree that bears yellow or orange yellow, trumpet like flowers and its fruit is deep $\mathrm{red} / \mathrm{black}$ in colour enhancing a large seed that bears some resemblance to a Chinese "Lucky nut" Leaves are covered in waxy coating to reduce water loss.

The physical properties of the fruit and kernel are unique and different from other tree borne oil seeds. Activities related to the fruits and kernels will require modifications in the processes and structures prevailing for other tree born oil seeds.

Hence in the present study an effort has been made to assess the toxic effect of $T$. peruviana against the filarial vector Culex quinquefasciatus.

\section{Materials and Methods}

\section{Collection of plant materials}

The fresh, leaves of Thevetia Peruviana (Apocynaceae) were collected from rural areas of Veerappam palayam village, Idappadi Taluk, Salem District Tamilnadu. The plants were authentified at BSI (Botanical Survey of India) and the specimens were deposited at Zoology Department, Erode Arts and Science College, Erode.

\section{Preparation of plant extracts}

The plant materials of Thevetia Peruviana leaves were washed with tap water, shade dried at room temperature and powdered by an electrical blender. Material was extracted with $300 \mathrm{ml}$ of methanol for 8 hours in a soxhlet apparatus (Vogel, 1978). The crude plant extracts were evaporated to dryness in rotary vaccum evaporator.

\section{Preparation of extract}

After collection, fresh leaves were washed in running - tab water and the stems were removed before use, and air dried in the shade for 15days. The dried leaves were ground to powder in electric grinder to obtain fine powder. The powder was then stored in air tight glass jars in a cool place away from sunlight. The Thevetia peruviana leaf powder $50 \mathrm{~g}$ with methanol $(300 \mathrm{ml}$ fine) in a soxhlet apparatus (boiling point range $60-65^{\circ} \mathrm{c}$ ) for 4 hours, according to the techniques of Imaga et al.,(2010),After extraction the soxhelt were cool in a room temperature. The extract were filtered through a Buchner funnel with Whatman no 1(125) filter paper. The filtered materials were taken into a round bottom flask and then condensed by evaporation of solvent in a ethanol extract respectively. After the evaporation of solvent from filtrate, the crude extract was weighed, the yields was $24 \%$ and the condensed extracts were preserved in tightly covered - labelled and stored in a cooling incubator at $4^{\circ} \mathrm{C}$ and until their use for insect bioassays.

\section{Preparation of required plant extracts concentration}

One gram of plant residue was dissolved in $100 \mathrm{ml}$ of acetone (stock solution) considered as $1 \%$ stock solution. Each different concentration was prepared from stock solution ranging from 2 to 10 .

\section{Results and Discussion}

The present work was carried out in filarial vector Culex quinquefaciatus to evaluate the general development life cycle, rate of mortality, longevity, fecundity and repellency using Thevetia peruviana leaf extract. The 
work mainly aims at the effect of alternative pesticide control for commonly used chemical pesticides. Observation was carried out in sub lethal concentration of plant extract.

\section{Biology of Culex quinquefaciatus}

Culex mosquito usually lay their eggs are laid one at time, struck together to form a raft of about 250-350 eggs. A raft of eggs looks like a speck of soot floating on the water surface and is about 1/4 inch long and 1/8 inch wide. The number of eggs per raft ranged from $105-280$.

\section{Morphometric analysis and Incubation period}

Incubation period ranged from 3 to 5 days, the mean being $4.33 \pm 0$. 50 days. The minimum percentage of hatching recorded was 87.33 and the maximum was 90. The first instar larva was $1.69 \pm 0.003 \mathrm{~mm}$ long and $0.81 \pm$ $0.006 \mathrm{~mm}$ broad.

The stadial period extended upto $2.66 \pm 0.130$ days. The length of second instar larva was $3.08 \pm 0.028 \mathrm{~mm}$, breadth was $0.81 \pm 0.014 \mathrm{~mm}$ and the larval duration was $2.33 \pm 0.130$ days.

The third instar larva was 4.90. $\pm 0.073 \mathrm{~mm}$ long, $2.84 \pm 0.035 \mathrm{~mm}$ broad and the larval duration was $3.33 \pm 0.128$ days.

The length of the fourth instar larva was 5.22 \pm $0.063 \mathrm{~mm}$, width was $3.1 \pm 0.011 \mathrm{~mm}$ and the larval duration was $2.33 \pm 0.130$ days. The pupa was comma shaped, $3.85 \pm 0.027 \mathrm{~mm}$ long and $1.99 \pm 0.042 \mathrm{~mm}$ broad.

\section{The $\mathrm{LC}_{50}$ value of Culex quinquefaciatus}

The insecticidal activity of Thevetia peruviana on Culex quinquefaciatu showed with $\mathrm{LC}_{50}$ value of $100 \mathrm{ppm}$. The extract showed fluctuation in limit of $\mathrm{LC}_{50}$ values from 250 to 360ppm (Fig. 1).

\section{Mortality rate of Culex quinquefaciatus}

Thevetia peruviana leaf extract was used on Culex quinquefaciatus and exposed at different sub lethal concentration such as 250ppm, 300ppm, 350ppm and 400ppm for continuous exposure period of 96 hours. The mortality rate of Culex quinquefaciatus was significantly influenced by Thevetia peruviana leaf extract at $250 \mathrm{ppm}$ concentration on 24 , 48,72 , and 96 hours duration of exposure period. Mortality of I instar larvae was recorded as $20.00 \pm 1.539,24.33 \pm 1.351$, $25.33 \pm 0.128,25.33 \pm 0.382$. Mortality of II instar larvae observed was $11.33 \pm 0.898$, $12.00 \pm 1.154,18.66 \pm 0.513$ and $19.67 \pm$ 0.899 . In III instar larvae the mortality was $8.66 \pm 0.513,11.66 \pm 0.898,13.33 \pm 0.128$ and $14.33 \pm 1.094$. In IV instar larvae mortality was $8.33 \pm 0.898,11.33 \pm 0.513,13.33 \pm$ 0.739 and $13.00 \pm 1.154$. Mortality of pupa was found as $2.66 \pm 0.572,3.66 \pm 0.572,6.66$ \pm 0.513 and $10.33 \pm 0.128$ compared with their respective controls (Table -1 ).

The mortality rate of Culex quinquefaciatus was increased with Thevetia peruviana leaf extract at 300ppm concentration on exposure for 96 hours. In the larval stages of Culex quinquefaciatus mortality rate was in I instar $28.00 \pm 1.539,30.66 \pm 0.513,35.33 \pm 0.128$ and $40.33 \pm 0.128$. In II instar larva it was recorded as $23.33 \pm 0.767,25.66 \pm 0.135$, $28.33 \pm 0.128$ and $32.00 \pm 1.154$. In III instar mortality rate was $22.00 \pm 1.539,24.66 \pm$ $0.130,26.66 \pm 0.898$ and $33.33 \pm 0.513$. In IV instar the mortality rate was $18.00 \pm 1.539$, $21.66 \pm 0.130,24.66 \pm 0.898$ and $28.33 \pm$ 0.513 . Mortality rate of pupa was $5.66 \pm$ $0.128,6.33 \pm 0.128,8.33 \pm 0.891$ and $10.66 \pm$ 0.512 present generally (Table 2). Culex quinquefaciatus mortality rate was recorded with 350ppm concentration at 96 hours exposure recorded in I instar was $32.33 \pm$ $0.128,35.33 \pm 0.513,39.66 \pm 0.758$ and 42.00 \pm 0.384 respectively. 
Table.1 Biology of Culex quinquefaciatus

\begin{tabular}{|c|c|c|c|c|}
\hline S. No & Parameters & Days X \pm SE & Parameters & Percentage \\
\hline $\mathbf{1}$ & Larval duration & $4.33 \pm 0.50$ & Hatchability & $86.33 \pm 6.285$ \\
\hline $\mathbf{2}$ & Incubation period & & Larval survival & 100 \\
\hline & i). I instar & $2.66 \pm 0.130$ & & \\
\hline & ii). II instar & $2.33 \pm 0.130$ & & \\
\hline & iii). III instar & $3.33 \pm 00.129$ & & 100 \\
\hline & iv). IV instar & $2.33 \pm 0.130$ & Pupal survival & 100 \\
\hline & Pupal duration & $2.66 \pm 0.513$ & Adult emergence & \\
\hline
\end{tabular}

Table.2 Morphometric analysis of larvae and pupae

\begin{tabular}{|c|c|c|c|c|c|c|c|c|c|}
\hline \multirow{2}{*}{ S.No } & \multirow{2}{*}{ Life stages } & \multicolumn{2}{|c|}{ Head } & \multicolumn{2}{|c|}{ Thorax } & \multicolumn{2}{|c|}{ Abdomen } & \multicolumn{2}{|c|}{ Total } \\
\hline & & Length & Width & Length & Width & Length & Width & Length & Width \\
\hline 1 & I instar & $\begin{array}{c}0.32 \\
\pm \\
0.732\end{array}$ & $\begin{array}{c}0.30 \\
\pm \\
0.962\end{array}$ & $\begin{array}{c}0.33 \\
\pm \\
0.001\end{array}$ & $\begin{array}{c}0.29 \\
\pm \\
0.577\end{array}$ & $\begin{array}{c}1.04 \\
\pm \\
0.002\end{array}$ & $\begin{array}{c}0.22 \\
\pm \\
0.577\end{array}$ & $\begin{array}{c}1.69 \\
\pm \\
0.003\end{array}$ & $\begin{array}{c}0.81 \\
\pm \\
0.006\end{array}$ \\
\hline 2 & II instar & $\begin{array}{c}0.55 \\
\pm \\
0.067\end{array}$ & $\begin{array}{c}0.62 \\
\pm \\
0.038\end{array}$ & $\begin{array}{c}0.57 \\
\pm \\
0.036\end{array}$ & $\begin{array}{c}0.66 \\
\pm \\
0.009\end{array}$ & $\begin{array}{c}1.99 \\
\pm \\
0.005\end{array}$ & $\begin{array}{c}0.53 \\
\pm \\
0.005\end{array}$ & $\begin{array}{c}3.08 \\
\pm \\
0.028\end{array}$ & $\begin{array}{c}1.81 \\
\pm \\
0.014\end{array}$ \\
\hline 3 & III instar & $\begin{array}{c}0.86 \\
\pm \\
0.011\end{array}$ & $\begin{array}{c}1.02 \\
\pm \\
0.021\end{array}$ & $\begin{array}{c}0.94 \\
\pm \\
0.010\end{array}$ & $\begin{array}{c}1.02 \\
\pm \\
0.006\end{array}$ & $\begin{array}{c}3.19 \\
\pm \\
0.037\end{array}$ & $\begin{array}{c}0.80 \\
\pm \\
0.003\end{array}$ & $\begin{array}{c}4.99 \\
\pm \\
0.073\end{array}$ & $\begin{array}{c}2.84 \\
\pm \\
0.035\end{array}$ \\
\hline 4 & IV instar & $\begin{array}{c}0.79 \\
\pm \\
0.012\end{array}$ & $\begin{array}{c}0.92 \\
\pm \\
0.009\end{array}$ & $\begin{array}{c}1.02 \\
\pm \\
0.012\end{array}$ & $\begin{array}{c}1.26 \\
\pm \\
0.015\end{array}$ & $\begin{array}{c}3.04 \\
\pm \\
0.015\end{array}$ & $\begin{array}{c}0.92 \\
\pm \\
0.009\end{array}$ & $\begin{array}{c}5.22 \\
\pm \\
0.063\end{array}$ & $\begin{array}{c}3.01 \\
\pm \\
0.011\end{array}$ \\
\hline & & Cepha & horax & & & & & & \\
\hline 5 & Pupa & $\begin{array}{c}1.28 \\
\pm \\
0.009\end{array}$ & $\begin{array}{c}1.29 \\
\pm \\
0.011\end{array}$ & & & $\begin{array}{c}2.56 \\
\pm \\
0.038\end{array}$ & $\begin{array}{c}0.70 \\
\pm \\
0.015\end{array}$ & $\begin{array}{c}3.85 \\
\pm \\
0.027\end{array}$ & $\begin{array}{c}1.99 \\
\pm \\
0.042\end{array}$ \\
\hline
\end{tabular}


Fig.1 The $\mathrm{LC}_{50}$ value of Thevetia peruviana leaf extract of Culex quinquefaciatus

I instar

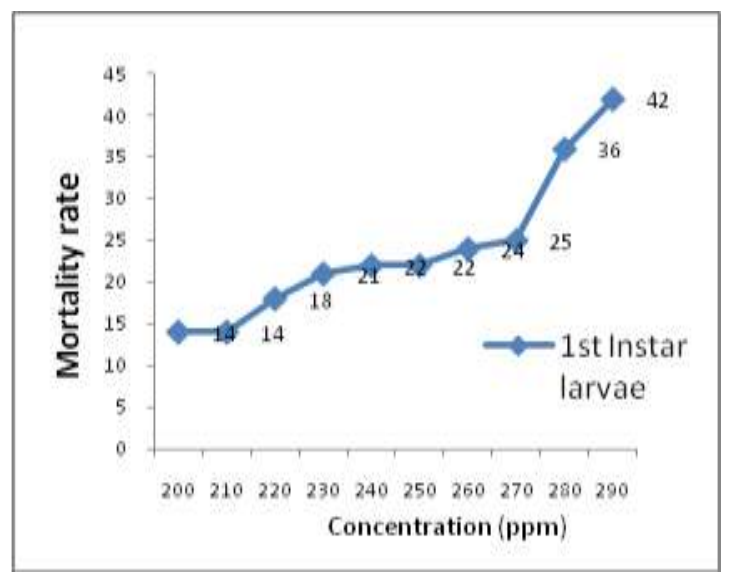

III instar

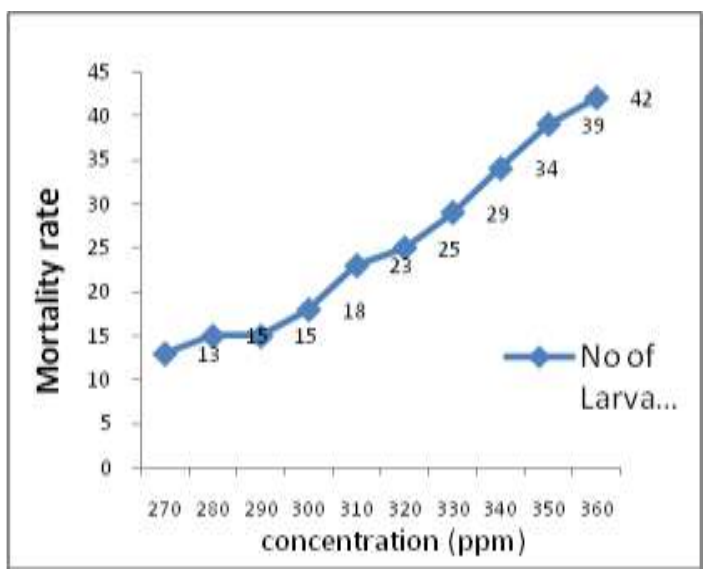

II instar

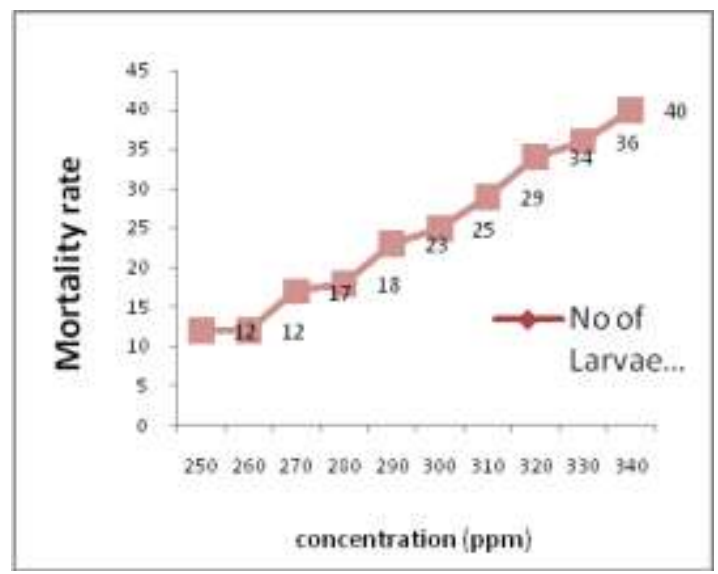

IV instar larva

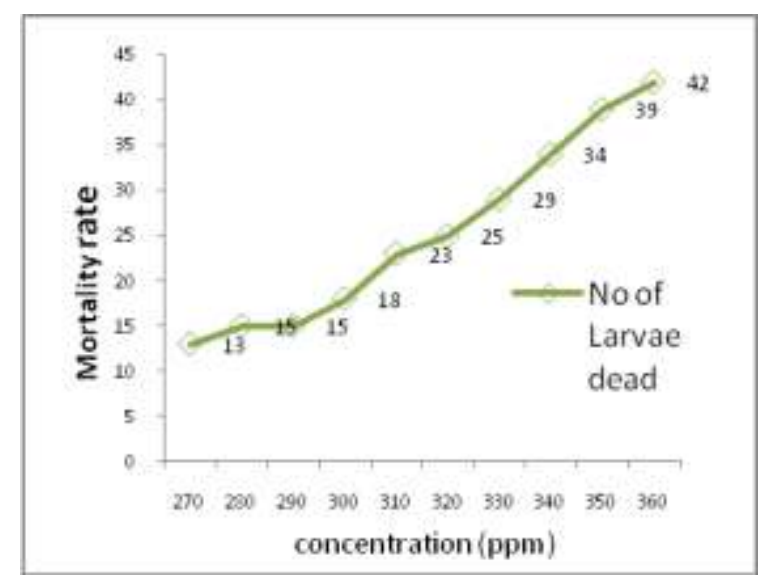

\section{Pupa}

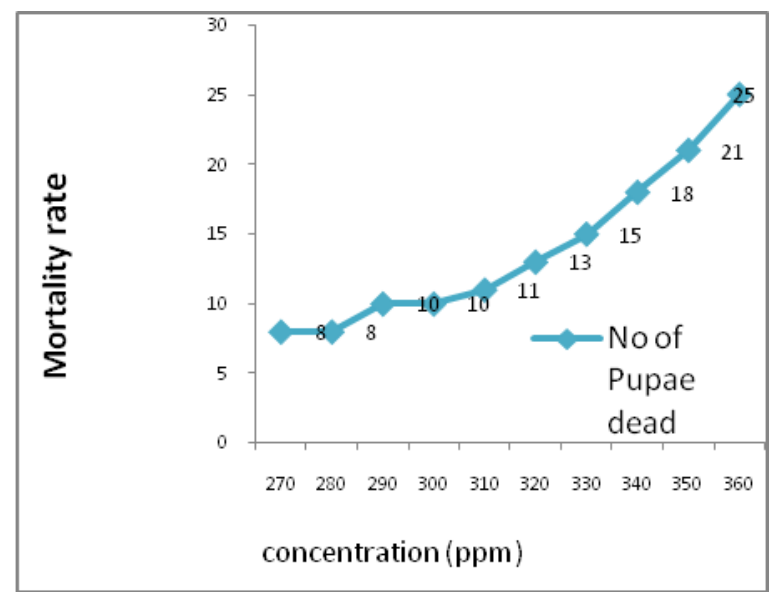


Table.3 Phytochemical screening of Methanolic extract of Thevetia peruviana leaves

\begin{tabular}{|c|c|c|}
\hline $\begin{array}{c}\text { Phytochemicals } \\
\text { observed }\end{array}$ & Test performed & Results \\
\hline Alkaloids & Dragendorff's test & - \\
\hline Flavinoids & Shinoda test & + \\
\hline Terpinoids & Noller's test & - \\
\hline Tannins & Neutral FeCl & + \\
\hline Saponins & Chloroform and $\mathrm{H}_{2} \mathrm{SO}_{4}$ & + \\
\hline Cardiac glycosides & Keller - Killani test & + \\
\hline Phlobatannins & Hydrochloric acid test & + \\
\hline Steriods & Acetic anhydride and $\mathrm{H}_{2} \mathrm{SO}_{4}$ & \\
\hline
\end{tabular}

Legend: + = Present - = Absent

II instar was $24.33 \pm 0.128,28.66 \pm 0.513$, $31.00 \pm 0.384$ and $36.33 \pm 1.661$. III instar the mortality rate was $20.33 \pm 0.128,23.00 \pm$ $0.384,28.33 \pm 0.128$ and $31.66 \pm 0.513$. IV instar mortality rate was $21.00 \pm 0.384,23.33$ $\pm 0.513,25.66 \pm 0.130$ and $31.33 \pm 1.661$. Mortality rate of pupa was $8.66 \pm 0.513,9.00$ $\pm 0.384,10.66 \pm 0.513$ and $11.66 \pm 0.130$ it was treated with jars respectively (Fig. 1).

The mortality rate of Culex quinquefaciatus were significantly affected by Thevetia peruviana leaf extract at 400ppm concentration was observed in I instar $32.66 \pm$ $0.130,38.33 \pm 0.130,41.66 \pm 0.893$ and 44.66 \pm 0.893 . II instar mortality rate was $27.00 \pm$ $0.384,32.33 \pm 0.513,35.66 \pm 0.128$ and 38.00 \pm 0.130 . III instar mortality rate was $23.66 \pm$ 1.670, $25.66 \pm 0.898,29.66 \pm 0.898$ and 32.60 \pm 1 154.IV instar mortality rate was $21.66 \pm$ $0.898,24.00 \pm 1.539,27.00 \pm 0.384$ and 30.00 \pm 1.154 . In pupa mortality rate was $9.33 \pm$ $0.518,11.00 \pm 0.384,11.33 \pm 0.128$ and 12.66 \pm 0.130 respectively (Fig. 1 ).

The result also demonstrated that the highest mortality of Culex quinquefaciatus I instar $42.00 \pm 0.384$, II instar $36.33 \pm 1.661$, III instar $31.66 \pm 0.513$, IV instar $31.33 \pm 1.661$ and pupa $11.66 \pm 0.130$ occurred at $350 \mathrm{ppm}$ concentration of Thevetia peruviana at 96 hours post application. The mortality rate was increased with increasing concentration.

The results revealed that the mortality rate was increased after the increase of concentration and the larvae. On the other hand, Al-Sharook et al.,(1991) reported that the death of treated insects may be due to inability of the molting bodies to swallow sufficient volume of air to split the old cuticle and expand the new one during ecdysis or to a metamorphosis inhibiting effect of the plant extract which is possibly based on the disturbance of the hormonal regulation. The $100 \%$ mortality might be due to the chemical constituents present in the methanol leaf extract $T$. peruviana that arrest the metabolic activity of the larvae, which caused the high percentage of mortality. Earlier authors reported that the methanol extract of $\mathrm{LC}_{50}$ value of $20.57 \mathrm{mg} / \mathrm{L}$, Culex quinquefasciatus, respectively (Govindarajan et al., 2014).

The methanol extract of $T$. peruviana was subjected to preliminary phytochemical analysis. The result showed the presence of alkaloid, glycosides, phenol, Flavinoids, Terpinoids, Saponins, Cardiac glycosides, Phlobatannins and Steriods but Alkaloids, Tannins were absent in methanol leaf extract of $T$. peruviana (Table 3 ). 


\section{References}

Abbott, W.S. (1925) A method of computing the effectiveness of insecticides. $J$. Econ. Entomol, 18: 267 - 269.

Anees, A. M. (2008). Larvicidal activity of Ocimum sanctum $L$. (Labiatae) against Aedes aegypti (L.) and Culex quinquefasciatus (Say). Parasitol. Res. $103: 425-453$.

Edeoga, H.O., Okwu, D.E. and Mbaebie B.O. (2005). Phytochemical constituents of some Nigerian medical plants. Afr. $J$. Biotech. 4(7): 685-688.

Asman,S.M., Mc Donald, P.T. and Prout, T. (1981). Field studies of genetic control systems for mosquitoes. Annual Review of entomology, 26: 289-318.

Bowers,W.S. (1992). Bionational approaches for Insect control. Korean, Journal of Applied Entomology., 31: 289 - 303.

Davidson G. Alternative measures to insecticides for mosquito control. Pesticide Sci 1972; 3: 503-14.

Harbone,J.B.(1973). Phytochemical methods, London. Chapman and Hall, Ltd. 49 188.

Prakash A, Rao. J.(1997). Botanical pesticides in agriculture Lewis, Boca Raton.

Ranson et al., 2001H. Ranson, L. Rossiter, F. Ortelli, B. Jensen, X. Wang, C.W. Roth, F.H. Collins, J. Hemingway Identification of a novel class of insect glutathione s-transferases involved in resistance to DDT in the malaria vector Anopheles gambiae Biochem. J., 359
(2001), pp. 295-304

Shell, E.R. (1997).Resurgence of a deadly diseases. Aflantic Monthly 45-60.

Sukumar, K, Perich, M.J. and Boobar, L.R. (1991). Botanical derivatives in mosquito control: a review. J Am Mosq Control Assoc., 7: 210- 237.

Sofowara, A. (1993). Medical plants and Traditional medicine in Africa. Spectrum Books Ltd, Ibadan, Nigeria, p. 289.

Sutton, P.M. Vergara, X., Beckman. J., Nicas, M. and Das, R. (2007). Pesticide illness among flight attendants due to aircraft disinsection. American Journal of Industrial Medicine, 50(5):345-356.

Swezey, O.H. (1932). Some Observations on Forest Insects at the Nauhi Nursery.

Trease, G.E. and Evans, W.C. (1996). Pharmacognosy, 14th edition, WB Saunders Company Ltd. UK. Pp. 1098 $-1115$.

Vargas,H.(1987). Frequency and effect of pox-like lesions in Galapagos Mockingbirds. Journal of Field Ornithology, 58:101-102.

WHO.(1995). Report of the informal consultation on aircraft disinfection. WHO/HQ, Geneva, 6-10 November 1995. Geneva, Switzerland: International Programme on Chemical Safety, World Health Organization: 57.

WHO. (2009). Country profile of Environmental Burden of Disease: Burundi. Geneva, Switzerland. World Health Organization.

\section{How to cite this article:}

Uthirasamy, S., T. Chitra and Manjula, G. 2019. A Study on Phytochemical Analysis and Toxicity Effect of Thevetia peruviana (pers) Merr, against the Filarial Vector, Culex quinquefasiatus Say. Int.J.Curr.Microbiol.App.Sci. 8(10): 1819-1827. doi: https://doi.org/10.20546/ijcmas.2019.810.211 